\title{
Hepatitis $B$ reactivation in patients receiving cytotoxic chemotherapy - diagnosis and management
}

\author{
John S. Lubel ${ }^{1}$, Peter W. Angus ${ }^{2}$ \\ ${ }^{1}$ Department of Hepatology, Box Hill Hospital, Box Hill, Melbourne, Victoria, \\ Australia \\ ${ }^{2}$ Department of Gastroenterology Austin Hospital and The University of Melbourne, \\ Austin \& Northern Health, Victoria, Australia
}

Short title: Hepatitis B reactivation with chemotherapy

Corresponding Author:

Dr John Lubel, Department of Gastroenterology and Hepatology,

Box Hill Hospital, Nelson Road, Box Hill, Melbourne, Victoria 3128, Australia.

email: Johnlubel@hotmail.com

Tel + $61(0) 394965582$

Fax +61 (0)3 94963487

No conflicts of interest exist for any of the authors of this manuscript.

\section{Total manuscript word count $=3847$}

\footnotetext{
This is an Accepted Article that has been peer-reviewed and approved for publication in the Journal of Gastroenterology and Hepatology, but has yet to undergo copy-editing and proof correction. Please cite this article as an "Accepted Article"; doi: 10.1111/j.14401746. 2009.06243.x
} 


\section{Abstract}

Nearly one third of the world's population have been infected with hepatitis B and the virus is endemic in many Asian countries. With increasing life expectancy and the expected global increase in cancer, chemotherapy induced reactivation of hepatitis B is likely to become an increasing problem. Patients with significant levels of HBV DNA in serum prior to chemotherapy and patients receiving intensive chemotherapy for hematological malignancies appear particularly at risk. Most patients who suffer reactivation of hepatitis B are positive for HBsAg prior to chemotherapy and are therefore easily identifiable by routine screening. In addition, the very large population of patients who have been exposed to the virus and have apparently cleared the virus as assessed by serological testing (HBsAg negative/HBcAb positive) may also be at risk of reactivation. These patients should be monitored and in some cases receive prophylaxis during chemotherapy. Published experience with antiviral prophylaxis has largely been limited to the nucleoside analogue, lamivudine. The commencement of antiviral prophylaxis prior to chemotherapy and its continuation until restitution of normal host immunity is the cornerstone to effective prevention of hepatitis B reactivation. This review summarises the important issues related to HBV reactivation and suggests an algorithm for managing these patients in the clinical setting.

Abstract word count $=205$ 


\section{Introduction}

It is estimated that 2 billion people worldwide have been infected with the hepatitis B virus (HBV) and over 350 million are chronic carriers. The regional prevalence of chronic HBV varies widely. In areas of high endemicity in the Asia-Pacific region, it approaches $20 \%$, whilst in Australia $<1 \%$ of the population are HBsAg positive. ${ }^{1-3}$ Patients who have been infected with HBV are vulnerable to disease reactivation during immunosuppressive pharmacotherapy. The clinical consequences vary from asymptomatic elevation of hepatic enzymes to severe hepatitis and death from fulminant hepatic failure. In addition to the direct harm caused by HBV reactivation, patient care may be compromised because of the need to delay or prematurely cease chemotherapy. ${ }^{4}$ Over the last decade it has been recognised that HBV reactivation following chemotherapy can effectively be prevented by antiviral prophylaxis. This review summarises the recent advances in this area and provides guidelines for prevention and management.

\section{Background}

Perinatally acquired hepatitis B is usually followed by a prolonged period of immunotolerance. During this phase there are high levels of viral replication within the liver but little if any immune-mediated liver injury. This period, which may last for several decades, is usually followed by an immune clearance phase characterized by loss of tolerance, resulting in T-cell mediated lysis of HBV-infected hepatocytes, recruitment of inflammatory cells and active hepatitis. This typically results in asymptomatic and episodic elevations of alanine aminotransferase (ALT). However, liver injury can be more severe, resulting in clinical hepatitis that can occasionally lead to hepatic failure. In many patients the immune clearance phase eventually results in hepatitis $\mathrm{B}$ e antigen (HBeAg) seroconversion and progression to a phase of immune control of viral replication; in this phase there is minimal viral replication and resolution of necro-inflammation.

In patients who have previously achieved immune control of HBV, immunosuppressive therapy may allow viral replication to escape, resulting in spread of infection within the liver and an increase in circulating HBV DNA. Following completion of immunosuppressive therapy, restoration of the host's immune response may lead to an immune clearance-like response that results in widespread cytotoxic $\mathrm{T}$ cell-mediated lysis of infected hepatocytes and severe liver injury. This syndrome of so-called "Hepatitis B reactivation following chemotherapy" has been recognised for over thirty years ${ }^{5,6}$ and has been reported following treatment of a wide range of hematological malignancies and solid tumours. Reactivation largely occurs in patients with chronic hepatitis B (CHB) who are positive for hepatitis B surface antigen (HBsAg), but it can also affect previously infected patients who have apparently cleared the virus. These patients can be identified serologically by the presence of hepatitis B core antibody (HBcAb) in the absence of HBsAg.

Although reactivation of hepatitis B occurs most commonly in the setting of cancer chemotherapy, it may also follow the use of immunomodulatory therapy for non- 
malignant conditions. These include solid organ transplantation, infliximab therapy for inflammatory bowel disease and treatment of rheumatological diseases with corticosteroids, methotrexate, ${ }^{7-9}$ infliximab alone ${ }^{10,11}$ or in combination with other therapies. ${ }^{12,13}$

\section{Diagnosis and clinical outcomes of hepatitis $B$ reactivation}

Early studies of hepatitis B reactivation were hindered by a lack of uniformity in case definition and the relative insensitivity of previous methods used to measure viral replication. The current generally accepted definition of HBV reactivation or a flare following chemotherapy is the development of hepatitis with a serum ALT greater than three times the upper limit of normal or an absolute increase of $100 \mathrm{IU} / \mathrm{L}$, associated with a demonstrable increase in HBV DNA by at least a 10-fold, or an absolute increase to $>10^{8} \mathrm{IU} / \mathrm{mL} .^{14-16}$

The clinical presentation of HBV reactivation can range from asymptomatic anicteric elevation of hepatic enzymes to fulminant hepatitis. Icteric hepatitis is said to occur if the serum bilirubin is greater than twice the upper limit of the normal bilirubin concentration $(<15 \mu \mathrm{mol} / \mathrm{L})$. Typically, there is an increase in HBV DNA during or shortly after a cycle of chemotherapy which precedes any elevation of ALT by up to 3 weeks. Subsequently HBV DNA titres decrease, so at the time of clinical hepatitis, HBV DNA may be undetectable. ${ }^{4}$ As a result, in the absence of serial monitoring of HBV DNA, the preceding increase in viral replication may be missed. In order to make the diagnosis, other causes of hepatitis need to be excluded. These include chemotherapy-induced hepatic injury, tumour infiltration of the liver and concurrent infection with other viruses such as hepatitis A, Epstein-Barr virus (EBV), and cytomegalovirus (CMV). Rarely, hepatitis may be caused by tumour obstruction of the hepatic veins producing the Budd-Chiari syndrome.

HBV reactivation flares may also result in a delay or failure to complete chemotherapy. In a prospective study of patients with breast cancer treated with chemotherapy, premature cessation or delay in chemotherapy occurred in $71 \%$ of patients with HBV reactivation compared to $33 \%$ of patients without evidence of reactivation. ${ }^{4}$

\section{Incidence and risk factors for hepatitis B reactivation}

Because serial HBV DNA monitoring is not widely performed in patients receiving chemotherapy outside the setting of clinical trials, the recorded incidence of HBV reactivation is likely to have been underestimated in many studies. Indeed, one trial demonstrated that using the above definition of reactivation hepatitis with conventional monitoring of HBV DNA (i.e. at the time of ALT rise), the incidence of HBV reactivation was $24 \%$ in chronic carriers of HBV receiving chemotherapy for breast cancer, whereas with serial HBV DNA monitoring, $41 \%$ of patients were identified as having HBV reactivation. ${ }^{4}$ 
The risk for HBV reactivation is influenced by both the type of malignancy and chemotherapeutic agent employed. Patients with lymphoma appear to be particularly at risk. ${ }^{15,16}$ Reactivation rates of $48 \%$ have been reported in HBsAg positive patients treated with chemotherapy for lymphoma, with an associated mortality of $4 \% .{ }^{17}$ Other studies report an incidence of HBV reactivation following chemotherapy for lymphoma between $24-67 \%$ and a mortality of $4-41 \% .{ }^{16-21}$ In part this very high incidence may be explained by the intensive chemotherapy necessary for lymphoma, but also may be due to the relatively high prevalence of HBV infection observed in patients with this condition. ${ }^{16,22-24}$ Patients receiving intensive cytoreductive therapy and high dose chemotherapy prior to hematopoietic stem cell transplantation are also particularly susceptible to HBV reactivation, with rates approaching $50 \%{ }^{25-29}$ The level of viral replication prior to chemotherapy appears the most important risk factor for $\mathrm{HBV}$ recurrence in this group. ${ }^{25}$

In patients receiving chemotherapy for non-hematological tumours, the highest rates of $\mathrm{HBV}$ reactivation have been reported in patients with breast cancer where the incidence ranges between $41-56 \%{ }^{4,30}$ The rate of reactivation appears to be lower in patients treated for other solid tumors, ranging between 14 and $21 \%$ in different studies. ${ }^{16,31,32}$ These differences are most likely due to the types of chemotherapy used for these conditions rather than the nature of the malignancy per se. In particular, the use of chemotherapy regimens containing corticosteroids and anthracycline containing regimens increase the risk of reactivation. ${ }^{15,16,18,22,33}$ The increased risk associated with corticosteroids is thought to be due to both an immunosuppressive effect and direct stimulation of viral replication via a glucocorticoid responsive element on the HBV genome. ${ }^{34}$

In patients with HBV cirrhosis, the treatment of hepatocellular carcinoma (HCC), with trans-arterial chemo-lipiodolization (TACE) appears to be associated with particularly high rates of HBV reactivation. In a recent study, reactivation of HBV occurred in 34\% of HBsAg positive patients who received TACE. The only independent predictor for reactivation in this study was seropositivity for $\mathrm{HBeAg}^{35}$ The risk of HBV reactivation following systemic chemotherapy for HCC is also high, with a reported rate of $36 \%$ in a prospective study of 102 HBsAg-positive patients. ${ }^{36}$ In this study, the mortality from reactivation reached $30 \%$, and interruption to chemotherapy occurred in $86 \% .^{36}$

There also appears to be an independent increase in the risk of HBV reactivation in patients receiving the anti-CD20 monoclonal antibody, rituximab. ${ }^{37}$ This drug is commonly used in conjunction with standard CHOP chemotherapy (cyclophosphamide, doxorubicin, vincristine, and prednisone so-called R-CHOP) for diffuse large-B-cell lymphoma at clinical stage II, III or IV (NICE guidelines September 2003). ${ }^{38,}{ }^{39}$ However, there are also numerous case reports of HBV reactivation following the use rituximab as monotherapy, ${ }^{40}$ or in combination with other types of chemotherapy. ${ }^{40-47}$

A number of host and viral factors predispose to HBV reactivation. These include male gender, ${ }^{16,17}$ younger age ${ }^{16}$ and HBeAg positive serology. ${ }^{16}$ The highest risk of hepatitis B reactivation occurs in HBsAg positive patients with detectable levels of viral replication prior to chemotherapy. ${ }^{16,25,48} \mathrm{HBV}$ DNA levels $>20,000 \mathrm{IU} / \mathrm{ml}$ may be one of the most important risk factors in patients undergoing autologous 
hematopoietic stem cell transplantation. ${ }^{15,25}$ Patients who have apparently cleared the virus, based on serological profile (HBcAb positive but HBsAg negative), may still undergo reactivation of HBV, although the risk is substantially lower than in HBsAgpositive patients, as discussed below.

\section{Reactivation in HBsAg-negative HBcAb positive patients}

With the advent of highly sensitive PCR techniques for detecting HBV DNA in serum and liver, it has been shown that most HBsAg negative/HBcAb positive patients who have achieved immune control of HBV replication have HBV DNA sequences detectable in the liver and/or serum. ${ }^{49}$ In these patients, who have apparently cleared HBV infection, immunosuppression can allow active viral replication to recommence, resulting in the re-emergence of HBsAg, a state commonly referred to as reverse seroconversion or seroreversion. ${ }^{14}$ HBsAg-negative patients in whom serum HBV DNA can still be detected are referred to as having occult HBV infection. HBV DNA is more often detected in patients positive for $\mathrm{HBcAb}$ but negative for $\mathrm{HBsAb}$, presumably because these patients lack the neutralising effect of HBsAb. ${ }^{50}$ Patients with occult HBV infection usually have low titres of HBV DNA detectable in the circulation (generally $<200 \mathrm{IU} / \mathrm{ml}$ ), ${ }^{50-53}$ and hepatitis B viral sequences can also be detected in liver tissue ${ }^{54,55}$. The prevalence of occult infection in patients positive for $\mathrm{HBcAb}$ is estimated to be between 11 and $80 \%$ depending on the degree of hepatic fibrosis in the population studied. ${ }^{51}$ Not surprisingly, patients with occult infection appear to be at higher risk for HBV reactivation than HBcAb positive/ HBV DNA negative patients. ${ }^{37}$

The true incidence of chemotherapy-induced reactivation of hepatitis $B$ in these patients is uncertain. Lok and colleagues performed a prospective study of HBV reactivation in 100 Chinese patients who received chemotherapy for lymphoma. Fiftyone of these patients had evidence of previous hepatitis B exposure (HBcAb positive with or without HBsAb). Following chemotherapy, reactivation hepatitis occurred in $4 \%$, none of whom died, compared to $48 \%$ in patients who were HBsAg positive at the time of chemotherapy, in whom the mortality reached $8 \% .{ }^{17}$ More recently, in a retrospective analysis of $319 \mathrm{HBcAb}$ positive/HBsAg negative patients receiving chemotherapy for lymphoma, reactivation of hepatitis B occurred in just over $1 \%$. However in the 74 patients in this study who received chemotherapy in combination with rituximab, the reactivation rate was $2.7 \%{ }^{56}$ There are now a number of case reports of fatal reactive hepatitis in $\mathrm{HBcAb}$ positive patients who received rituximab containing chemotherapy for lymphoma. ${ }^{42,46,57-59}$

In the setting of allogenic hematopoietic stem cell transplantation seroreversion is far more common than following standard chemotherapy; it occurs in $40 \%$ at 2 years and $70 \%$ of patients at 5 years post-transplantation. ${ }^{60}$ With prolonged follow-up, the rate of seroreversion in one case series approached $100 \% .{ }^{61}$ Patients with graft-versus host disease appear more likely to undergo seroreversion and represent a particularly highrisk group. ${ }^{62}$ It has been proposed that a drop in HBsAb titre can identify patients at risk of seroreversion and who are likely to benefit from antiviral prophylaxis. ${ }^{60,63}$ However, this approach is not applicable to HBsAb-negative, HBcAb positive patients and remains untested in other patient populations. Reactivation has also been 
described in $\mathrm{HBcAb}$ positive/HBsAg negative patients following organ transplantation, ${ }^{64}$ although the relative risk of reactivation is low and routine anti-viral therapy is generally not used in this patient group. ${ }^{65}$

\section{Preventing HBV reactivation following chemotherapy}

\section{Who should be screened?}

The most important first step in avoiding the serious morbidity associated with HBV reactivation is to identify patients at risk before they undergo chemotherapy. Clearly, in areas of high HBV endemicity all patients should be screened for HBsAg and $\mathrm{HBcAb}$ prior to immunosuppressive chemotherapy. There are many immunosuppressive therapies that carry a low risk of HBV reactivation, and are so widely used to make routine HBV screening in low risk populations impractical. These include short courses of corticosteroids alone, and widely used immunosuppressant medications such as methotrexate and azathioprine when used as monotherapy. In patients who receive treatment with these lower risk therapies it is reasonable to confine screening to those with a significant risk of HBV infection. Such patients include those with a history of drug use, men who have sex with men and immigrants from areas of high HBV endemicity. However, there is a strong argument that screening should be performed in all patients receiving chemotherapy regimes that are associated with a high risk of reactivation (eg chemotherapy for hematological malignancies and breast cancer), independent of the likelihood of HBV infection, given that the cost of screening for HBsAg is relatively low whereas the clinical consequences of reactivation can be life-threatening.

\section{Which antiviral drug should be used?}

There is now clear evidence that the risk of reactivation can be greatly reduced by identifying at risk patients prior to chemotherapy and the use of prophylactic antiviral therapy. Although there are now five oral agents approved for the treatment of chronic hepatitis B (lamivudine, adefovir, entecavir, tenofovir, telbivudine), the published experience in the prevention and treatment of HBV reactivation following chemotherapy is almost entirely limited to lamivudine.

This drug has proven efficacy and safety in preventing HBV reactivation following chemotherapy for both hematological and solid malignancies. ${ }^{20,21,28,30,66-75}$ A major concern with its prolonged use is the possibility of viral breakthrough following the emergence of resistance mutations in the YMDD region of the HBV-DNA polymerase. In non-immunosupressed patients with chronic hepatitis $B$, the cumulative rate of drug resistance is $24 \%$ after 1 year and $65-70 \%$ after 5 years of lamivudine monotherapy. ${ }^{76}$ It appears that rates of lamivudine resistance may be similar in patients receiving prophylaxis to prevent chemotherapy induced reactivation. ${ }^{77}$ Importantly, cases of severe HBV reactivation hepatitis and hepatic decompensation have been reported following development of lamivudine resistance. $^{78}$ 
Alternative antiviral agents such adefovir, entecavir or tenofovir are likely to be at least as effective as lamivudine in preventing HBV reactivation and have significantly lower resistance rates. Adefovir has been used to rescue chemotherapy patients with established HBV reactivation ${ }^{79}$ and patients treated with lamivudine prophylaxis who have developed drug resistance. ${ }^{80}$ However, this drug is the least potent of the currently available antivirals, primary treatment failure occurs in $10 \%$ or more of patients, and resistance occurs at a rate of $30 \%$ by the end of 4 years. ${ }^{81}$ Both entecavir and tenofovir are more attractive candidates given their high potency and extremely low resistance rates. However, they are significantly more expensive than lamivudine, and randomised studies using these drugs for prophylaxis in the setting of chemotherapy are lacking. ${ }^{82}$

\section{When and for how long should antiviral therapy be given?}

The optimal timing for initiation of antiviral therapy has not been clearly established. Intuitively, starting antiviral drugs before chemotherapy seems logical since this should pre-empt any increase in viral replication, reduce the likelihood of drug resistance and minimise the risk of a flare once chemotherapy is stopped. ${ }^{28}$ Importantly, patients who already have active HBV disease (with significant levels of HBV DNA and raised ALT) when first identified at pre-chemotherapy screening should have their disease treated immediately, with the aim of minimising viral replication and disease activity before chemotherapy is given.

In patients at high risk of HBV reactivation, it is preferable that antiviral therapy be started pre-emptively prior to chemotherapy, since this reduces the incidence and severity of reactivation hepatitis and allows chemotherapy to be completed. ${ }^{28,83}$ In contrast, deferring lamivudine treatment until HBV DNA levels become elevated is ineffective. In one randomised prospective study of patients receiving chemotherapy for lymphoma, HBV reactivation occurred in $87 \%$ of patients in whom lamivudine therapy was delayed in this manner. ${ }^{84}$ More recently, a multi-centre randomised prospective trial in patients with non-Hodgkin's lymphoma receiving CHOP examined the effect of prophylactic lamivudine versus therapeutic lamivudine (delaying antiviral therapy until elevations of ALT were observed). Hepatitis B reactivation occurred in $11.5 \%$ of patients treated pre-emptively, compared to $56 \%$ of patients treated therapeutically. ${ }^{21}$ A number of recent meta-analyses have now confirmed that pre-emptive lamivudine therapy reduces reactivation of $\mathrm{HBV}$ with a risk reduction estimated to be between $79 \%$ and $89 \% .{ }^{74,75,85}$ Furthermore, the number needed to treat with lamivudine to avoid a single reactivation is estimated to be three. $^{74}$

Pre-emptive antiviral therapy is not routinely recommended in HBsAg negative/HBcAb positive patients with undetectable HBV-DNA, since these patients are at much lower risk of reactivation than HBsAg-positive patients. However, patients with detectable HBV DNA (occult HBV infection) are at greater risk of seroreversion and subsequent reactivation hepatitis and it has been suggested that these patients be treated with lamivudine prior to chemotherapy. ${ }^{37,86}$ In occult infection, the alternative approach of deferring antiviral treatment until seroreversion and/or a significant rise in HBV-DNA has not been adequately assessed in clinical 
trials. Given the relative safety of oral antiviral therapy and the serious consequences of HBV reactivation, deferring treatment no longer can be recommended. ${ }^{37,87}$

The duration of antiviral prophylaxis is also contentious. Experience is limited to the use of lamivudine. It is likely that the optimal timing and duration of prophylaxis will depend in part on the antiviral drug used as well as the intensity of the immunosuppression together with a number of host and viral factors. In patients without evidence of active hepatitis B disease prior to chemotherapy, the most logical approach would be to provide antiviral cover until the immune system has fully recovered. In a prospective study of $46 \mathrm{HBsAg-positive} \mathrm{patients} \mathrm{with} \mathrm{haematological}$ malignancies in whom lamivudine prophylaxis was ceased 3 months after completing chemotherapy, reactivation of HBV occurred in 29\% following withdrawal of lamivudine. ${ }^{88}$ In this study, HBV DNA levels $\geq 2000 \mathrm{IU} / \mathrm{ml}$ appeared to confer additional risk of reactivation ( $50 \%$ vs $10 \%$ if $\mathrm{HBV}$ DNA $\leq 2000 \mathrm{IU} / \mathrm{ml}, P<0.001$ ). HBeAg positive patients were also more likely to experience HBV reactivation following lamivudine withdrawal. A number of other studies report cases of HBV reactivation and even fatal fulminant hepatitis when lamivudine was stopped 3 months or less after completion of chemotherapy. ${ }^{45,89,90}$ Similarly, in patients receiving rituximab-CHOP, cessation of lamividine 4 weeks after completion of chemotherapy was followed by episodes of HBV reactivation which occurred up to 6 months after treatment was withdrawn. ${ }^{44}$

It is clear from these studies that prophylactic antiviral therapy cannot safely be discontinued immediately after chemotherapy and that prolonged prophylactic period is required to adequately prevent viral flares. ${ }^{88}$ As a result of this experience, it has been suggested that prophylaxis be continued for at least 6 months after the chemotherapy has been completed. A recent decision analysis model for lamivudine pre-emptive therapy compared to expectant management (treatment only commenced when there was clinical evidence of reactivation) in lymphoma patients has shown that this approach is highly cost effective. ${ }^{91}$ For some therapies it may be possible to more precisely tailor the timing of prophylaxis discontinuation based on objective evidence that immune competency has been restored - for example, restoration of normal CD20 counts after rituximab therapy. ${ }^{14}$

\section{Treatment of established HBV reactivation in patients who have not received prophylactic anti-viral therapy}

Despite proven benefits of pre-emptive therapy compared to expectant management of $\mathrm{HBV}$ reactivation, ${ }^{21}$, 92 patients undergoing intensive chemotherapy are occasionally not screened for hepatitis $\mathrm{B}$ and reactivation is only identified when these patients present symptomatically with hepatitis. Under these circumstances, chemotherapy should be discontinued and treatment with antiviral agents commenced. There have been a number of reports claiming that lamivudine may prevent progressive hepatitis and even allow completion of chemotherapy in this situation. ${ }^{69}$, 93-95 However, pre-emptive therapy with lamivudine is far more effective at preventing HBV reactivation and its consequences compared to treating established reactivation hepatitis; this reinforces the importance of appropriate HBV screening of patients prior to chemotherapy. 


\section{Suggested algorithm for prevention of hepatitis B reactivation following chemotherapy:}

Figure 1 presents a simplified algorithm for the management of patients prior to chemotherapy.

All patients undergoing chemotherapy should be screened for previous exposure or current infection with HBV (serology for HBcAb and HBsAg). Patients with HBV disease in an active phase (with high HBV DNA and elevated ALT with active liver inflammation) and who fulfil criteria for commencing antiviral treatment should start therapy as per local protocols. All other patients with positive HBsAg (patients in the immune-tolerant phase or immune control phase) should start pre-emptive therapy with lamivudine (or another potent anti-HBV nucleos(t)ide analogue) one week prior to starting chemotherapy and continue for 6 months after its completion. Patients receiving lamivudine prophylaxis should be monitored with serial HBV DNA assays, and formal testing for lamivudine resistance should be performed if there is a 1 log increase in HBV DNA. ${ }^{86}$ Once resistance is confirmed, patients should be given adefovir in addition to lamivudine or changed to tenofovir if this is available.

Patients receiving intensive chemotherapy who are positive for HBcAb but HBsAg negative should have a sensitive HBV DNA assay performed to determine whether they have occult HBV infection. If HBV DNA is detected, these patients should be treated as for positive-HBsAg patients. Patients with undetectable HBV DNA should be monitored regularly during chemotherapy for evidence of HBV reactivation. The optimal monitoring schedule for these patients has not yet been ascertained. However it seems logical to perform regular measurement of HBsAb, HBsAg titres and HBV DNA after each cycle of chemotherapy since changes in these parameters are likely to precede changes in ALT and the development of clinically important hepatitis; this would allow antiviral treatment to be commenced in a timely fashion.

Recipients of hematopoietic stem cell transplants positive for HBcAb are likely to undergo seroreversion; they are then at risk of HBV reactivation. These patients should probably be treated with prophylactic lamivudine, as for the HBsAg-positive patients.

\section{Conclusion}

Chemotherapy-induced reactivation of hepatitis B may result in severe liver injury and prevent completion of life-saving treatment of the underlying malignancy. This potentially fatal complication can be effectively prevented by the use of oral antiviral medication prior to commencing chemotherapy. It is therefore paramount that all patients receiving intensive chemotherapy be screened for HBV. Most of the experience with antivirals in this setting has centred on lamivudine. Although drug resistance is a problem with long-term use of this drug, it has proven to be safe, well tolerated and highly effective in preventing HBV reactivation. All those involved in the use of immunosuppressive chemotherapy should be aware of the risk of HBV reactivation and understand the principles of prevention or management of this condition. Finally, it is very likely that alternative antiviral agents such as entecavir and tenofovir, will prove at least as effective as lamivudine however, they are currently more expensive and there is a need for further research to confirm their costefficacy in this setting. 


\section{References}

[1] Chen CJ, Wang LY, Yu MW. Epidemiology of hepatitis B virus infection in the Asia-Pacific region. J Gastroenterol Hepatol. 2000; 15 Suppl: E3-6.

[2] Gust ID. Epidemiology of hepatitis B infection in the Western Pacific and South East Asia. Gut. 1996; 38 Suppl 2: S18-23.

[3] Lavanchy D. Hepatitis B virus epidemiology, disease burden, treatment, and current and emerging prevention and control measures. J Viral Hepat. 2004; 11: 97107.

[4] Yeo W, Chan PK, Hui P, et al. Hepatitis B virus reactivation in breast cancer patients receiving cytotoxic chemotherapy: a prospective study. J Med Virol. 2003; 70: 553-61.

[5] Galbraith RM, Eddleston AL, Williams R, Zuckerman AJ. Fulminant hepatic failure in leukaemia and choriocarcinoma related to withdrawal of cytotoxic drug therapy. Lancet. 1975; 2: 528-30.

[6] Wands JR, Chura CM, Roll FJ, Maddrey WC. Serial studies of hepatitisassociated antigen and antibody in patients receiving antitumor chemotherapy for myeloproliferative and lymphoproliferative disorders. Gastroenterology. 1975; 68: 105-12.

[7] Gwak GY, Koh KC, Kim HY. Fatal hepatic failure associated with hepatitis B virus reactivation in a hepatitis B surface antigen-negative patient with rheumatoid arthritis receiving low dose methotrexate. Clinical and experimental rheumatology. 2007; 25: 888-9.

[8] Ito S, Nakazono K, Murasawa A, et al. Development of fulminant hepatitis B (precore variant mutant type) after the discontinuation of low-dose methotrexate therapy in a rheumatoid arthritis patient. Arthritis and rheumatism. 2001; 44: 339-42.

[9] Narvaez J, Rodriguez-Moreno J, Martinez-Aguila MD, Clavaguera MT. Severe hepatitis linked to B virus infection after withdrawal of low dose methotrexate therapy. The Journal of rheumatology. 1998; 25: 2037-8.

[10] Ojiro K, Naganuma M, Ebinuma H, et al. Reactivation of hepatitis B in a patient with Crohn's disease treated using infliximab. J Gastroenterol. 2008; 43: 397401.

[11] Esteve M, Saro C, Gonzalez-Huix F, Suarez F, Forne M, Viver JM. Chronic hepatitis B reactivation following infliximab therapy in Crohn's disease patients: need for primary prophylaxis. Gut. 2004; 53: 1363-5.

[12] Wendling D, Auge B, Bettinger D, et al. Reactivation of a latent precore mutant hepatitis B virus related chronic hepatitis during infliximab treatment for severe spondyloarthropathy. Annals of the rheumatic diseases. 2005; 64: 788-9. [13] Ostuni P, Botsios C, Punzi L, Sfriso P, Todesco S. Hepatitis B reactivation in a chronic hepatitis B surface antigen carrier with rheumatoid arthritis treated with infliximab and low dose methotrexate. Annals of the rheumatic diseases. 2003; 62: 686-7.

[14] Yeo W, Johnson PJ. Diagnosis, prevention and management of hepatitis B virus reactivation during anticancer therapy. Hepatology. 2006; 43: 209-20.

[15] Yeo W, Zee B, Zhong S, et al. Comprehensive analysis of risk factors associating with Hepatitis B virus (HBV) reactivation in cancer patients undergoing cytotoxic chemotherapy. Br J Cancer. 2004; 90: 1306-11. 
[16] Yeo W, Chan PK, Zhong S, et al. Frequency of hepatitis B virus reactivation in cancer patients undergoing cytotoxic chemotherapy: a prospective study of 626 patients with identification of risk factors. J Med Virol. 2000; 62: 299-307.

[17] Lok AS, Liang RH, Chiu EK, Wong KL, Chan TK, Todd D. Reactivation of hepatitis B virus replication in patients receiving cytotoxic therapy. Report of a prospective study. Gastroenterology. 1991; 100: 182-8.

[18] Nakamura Y, Motokura T, Fujita A, Yamashita T, Ogata E. Severe hepatitis related to chemotherapy in hepatitis B virus carriers with hematologic malignancies. Survey in Japan, 1987-1991. Cancer. 1996; 78: 2210-5.

[19] Kumagai K, Takagi T, Nakamura S, et al. Hepatitis B virus carriers in the treatment of malignant lymphoma: an epidemiological study in Japan. Ann Oncol. 1997; 8 Suppl 1: 107-9.

[20] Yeo W, Chan PK, Ho WM, et al. Lamivudine for the prevention of hepatitis B virus reactivation in hepatitis B s-antigen seropositive cancer patients undergoing cytotoxic chemotherapy. J Clin Oncol. 2004; 22: 927-34.

[21] Hsu C, Hsiung CA, Su IJ, et al. A revisit of prophylactic lamivudine for chemotherapy-associated hepatitis B reactivation in non-Hodgkin's lymphoma: a randomized trial. Hepatology. 2008; 47: 844-53.

[22] Takai S, Tsurumi H, Ando K, et al. Prevalence of hepatitis B and C virus infection in haematological malignancies and liver injury following chemotherapy. Eur J Haematol. 2005; 74: 158-65.

[23] Marcucci F, Mele A, Spada E, et al. High prevalence of hepatitis B virus infection in B-cell non-Hodgkin's lymphoma. Haematologica. 2006; 91: 554-7.

[24] Liang RH, Lok AS, Lai CL, Chan TK, Todd D, Chiu EK. Hepatitis B infection in patients with lymphomas. Hematol Oncol. 1990; 8: 261-70.

[25] Lau GK, Leung YH, Fong DY, et al. High hepatitis B virus (HBV) DNA viral load as the most important risk factor for HBV reactivation in patients positive for HBV surface antigen undergoing autologous hematopoietic cell transplantation. Blood. 2002; 99: 2324-30.

[26] Lau GK, Liang R, Chiu EK, Lee CK, Lam SK. Hepatic events after bone marrow transplantation in patients with hepatitis B infection: a case controlled study. Bone marrow transplantation. 1997; 19: 795-9.

[27] Liang R, Lau GK, Kwong YL. Chemotherapy and bone marrow transplantation for cancer patients who are also chronic hepatitis B carriers: a review of the problem. J Clin Oncol. 1999; 17: 394-8.

[28] Lau GK, He ML, Fong DY, et al. Preemptive use of lamivudine reduces hepatitis B exacerbation after allogeneic hematopoietic cell transplantation.

Hepatology. 2002; 36: 702-9.

[29] Knoll A, Boehm S, Hahn J, Holler E, Jilg W. Reactivation of resolved hepatitis B virus infection after allogeneic haematopoietic stem cell transplantation.

Bone marrow transplantation. 2004; 33: 925-9.

[30] Dai MS, Wu PF, Shyu RY, Lu JJ, Chao TY. Hepatitis B virus reactivation in breast cancer patients undergoing cytotoxic chemotherapy and the role of preemptive lamivudine administration. Liver Int. 2004; 24: 540-6.

[31] Alexopoulos CG, Vaslamatzis M, Hatzidimitriou G. Prevalence of hepatitis B virus marker positivity and evolution of hepatitis B virus profile, during chemotherapy, in patients with solid tumours. Br J Cancer. 1999; 81: 69-74.

[32] Kim MK, Ahn JH, Kim SB, et al. Hepatitis B reactivation during adjuvant anthracycline-based chemotherapy in patients with breast cancer: a single institution's experience. The Korean journal of internal medicine. 2007; 22: 237-43. 
[33] Cheng AL. Steroid-free chemotherapy decreases the risk of hepatitis flare-up in hepatitis B virus carriers with non-Hodgkin's lymphoma. Blood. 1996; 87: 1202.

[34] Tur-Kaspa R, Shaul Y, Moore DD, et al. The glucocorticoid receptor recognizes a specific nucleotide sequence in hepatitis B virus DNA causing increased activity of the HBV enhancer. Virology. 1988; 167: 630-3.

[35] Jang JW, Choi JY, Bae SH, et al. Transarterial chemo-lipiodolization can reactivate hepatitis B virus replication in patients with hepatocellular carcinoma. $J$ Hepatol. 2004; 41: 427-35.

[36] Yeo W, Lam KC, Zee B, et al. Hepatitis B reactivation in patients with hepatocellular carcinoma undergoing systemic chemotherapy. Ann Oncol. 2004; 15: 1661-6.

[37] Hui CK, Cheung WW, Zhang HY, et al. Kinetics and risk of de novo hepatitis B infection in HBsAg-negative patients undergoing cytotoxic chemotherapy.

Gastroenterology. 2006; 131: 59-68.

[38] Coiffier B, Lepage E, Briere J, et al. CHOP chemotherapy plus rituximab compared with CHOP alone in elderly patients with diffuse large-B-cell lymphoma. $N$ Engl J Med. 2002; 346: 235-42.

[39] Czuczman MS, Weaver R, Alkuzweny B, Berlfein J, Grillo-Lopez AJ. Prolonged clinical and molecular remission in patients with low-grade or follicular non-Hodgkin's lymphoma treated with rituximab plus CHOP chemotherapy: 9-year follow-up. J Clin Oncol. 2004; 22: 4711-6.

[40] Perceau G, Diris N, Estines O, Derancourt C, Levy S, Bernard P. Late lethal hepatitis B virus reactivation after rituximab treatment of low-grade cutaneous B-cell lymphoma. The British journal of dermatology. 2006; 155: 1053-6.

[41] Wasmuth JC, Fischer HP, Sauerbruch T, Dumoulin FL. Fatal acute liver failure due to reactivation of hepatitis B following treatment with fludarabine/cyclophosphamide/rituximab for low grade non-Hodgkin's lymphoma. European journal of medical research. 2008; 13: 483-6.

[42] Law JK, Ho JK, Hoskins PJ, Erb SR, Steinbrecher UP, Yoshida EM. Fatal reactivation of hepatitis $B$ post-chemotherapy for lymphoma in a hepatitis B surface antigen-negative, hepatitis B core antibody-positive patient: potential implications for future prophylaxis recommendations. Leuk Lymphoma. 2005; 46: 1085-9.

[43] Tsutsumi Y, Kawamura T, Saitoh S, et al. Hepatitis B virus reactivation in a case of non-Hodgkin's lymphoma treated with chemotherapy and rituximab: necessity of prophylaxis for hepatitis B virus reactivation in rituximab therapy. Leuk Lymphoma. 2004; 45: 627-9.

[44] Dai MS, Chao TY, Kao WY, Shyu RY, Liu TM. Delayed hepatitis B virus reactivation after cessation of preemptive lamivudine in lymphoma patients treated with rituximab plus CHOP. Ann Hematol. 2004; 83: 769-74.

[45] Ono K, Iyama S, Matsunaga T, et al. [Reactivation of hepatitis B virus due to rituximab plus CHOP after preemptive lamivudine administration in a patient with diffuse large B-cell lymphoma]. Gan to kagaku ryoho. 2007; 34: 1509-12.

[46] Sera T, Hiasa Y, Michitaka K, et al. Anti-HBs-positive liver failure due to hepatitis B virus reactivation induced by rituximab. Internal medicine (Tokyo, Japan). 2006; 45: 721-4.

[47] Tsutsumi Y, Kanamori H, Mori A, et al. Reactivation of hepatitis B virus with rituximab. Expert opinion on drug safety. 2005; 4: 599-608.

[48] Zhong S, Yeo W, Schroder C, et al. High hepatitis B virus (HBV) DNA viral load is an important risk factor for HBV reactivation in breast cancer patients undergoing cytotoxic chemotherapy. J Viral Hepat. 2004; 11: 55-9. 
[49] Tanaka Y, Esumi M, Shikata T. Persistence of hepatitis B virus DNA after serological clearance of hepatitis B virus. Liver. 1990; 10: 6-10.

[50] Brechot C, Thiers V, Kremsdorf D, Nalpas B, Pol S, Paterlini-Brechot P. Persistent hepatitis B virus infection in subjects without hepatitis B surface antigen: clinically significant or purely "occult"? Hepatology. 2001; 34: 194-203.

[51] Hu KQ. Occult hepatitis B virus infection and its clinical implications. J Viral Hepat. 2002; 9: 243-57.

[52] Rehermann B, Ferrari C, Pasquinelli C, Chisari FV. The hepatitis B virus persists for decades after patients' recovery from acute viral hepatitis despite active maintenance of a cytotoxic T-lymphocyte response. Nature medicine. 1996; 2: 1104-8.

[53] Cabrerizo M, Bartolome J, Caramelo C, Barril G, Carreno V. Molecular analysis of hepatitis B virus DNA in serum and peripheral blood mononuclear cells from hepatitis B surface antigen-negative cases. Hepatology. 2000; 32: 116-23.

[54] Fong TL, Di Bisceglie AM, Gerber MA, Waggoner JG, Hoofnagle JH. Persistence of hepatitis B virus DNA in the liver after loss of HBsAg in chronic hepatitis B. Hepatology. 1993; 18: 1313-8.

[55] Loriot MA, Marcellin P, Walker F, et al. Persistence of hepatitis B virus DNA in serum and liver from patients with chronic hepatitis B after loss of HBsAg. $J$ Hepatol. 1997; 27: 251-8.

[56] Targhetta C, Cabras MG, Mamusa AM, Mascia G, Angelucci E. Hepatitis B virus-related liver disease in isolated anti-hepatitis B-core positive lymphoma patients receiving chemo- or chemo-immune therapy. Haematologica. 2008; 93: 951-2.

[57] Dervite I, Hober D, Morel P. Acute hepatitis B in a patient with antibodies to hepatitis B surface antigen who was receiving rituximab. $N$ Engl J Med. 2001; 344:

68-9.

[58] Sarrecchia C, Cappelli A, Aiello P. HBV reactivation with fatal fulminating hepatitis during rituximab treatment in a subject negative for HBsAg and positive for HBsAb and HBcAb. J Infect Chemother. 2005; 11: 189-91.

[59] Westhoff TH, Jochimsen F, Schmittel A, et al. Fatal hepatitis B virus reactivation by an escape mutant following rituximab therapy. Blood. 2003; 102: 1930. [60] Onozawa M, Hashino S, Izumiyama K, et al. Progressive disappearance of anti-hepatitis B surface antigen antibody and reverse seroconversion after allogeneic hematopoietic stem cell transplantation in patients with previous hepatitis B virus infection. Transplantation. 2005; 79: 616-9.

[61] Knoll A, Boehm S, Hahn J, Holler E, Jilg W. Long-term surveillance of haematopoietic stem cell recipients with resolved hepatitis B: high risk of viral reactivation even in a recipient with a vaccinated donor. J Viral Hepat. 2007; 14: 47883.

[62] Seth P, Alrajhi AA, Kagevi I, et al. Hepatitis B virus reactivation with clinical flare in allogeneic stem cell transplants with chronic graft-versus-host disease. Bone marrow transplantation. 2002; 30: 189-94.

[63] Goyama S, Kanda Y, Nannya Y, et al. Reverse seroconversion of hepatitis B virus after hematopoietic stem cell transplantation. Leuk Lymphoma. 2002; 43: 215963.

[64] Berger A, Preiser W, Kachel HG, Sturmer M, Doerr HW. HBV reactivation after kidney transplantation. J Clin Virol. 2005; 32: 162-5.

[65] Duhart BT, Jr., Honaker MR, Shokouh-Amiri MH, et al. Retrospective evaluation of the risk of hepatitis B virus reactivation after transplantation. Transpl Infect Dis. 2003; 5: 126-31. 
[66] Cil T, Altintas A, Pasa S, Bayan K, Ozekinci T, Isikdogan A. Lamivudine for the prevention of hepatitis B virus reactivation in hepatitis-B surface antigen (HBSAG) seropositive cancer patients undergoing cytotoxic chemotherapy. Leuk Lymphoma. 2008; 49: 939-47.

[67] Lau GK, Lie A, Liang R. Prophylactic lamivudine therapy for hepatitis B patients undergoing immunosuppressive therapy. Blood. 2002; 100: 3054.

[68] Rossi G, Pelizzari A, Motta M, Puoti M. Primary prophylaxis with lamivudine of hepatitis B virus reactivation in chronic HbsAg carriers with lymphoid malignancies treated with chemotherapy. Br J Haematol. 2001; 115: 58-62.

[69] Ahmed A, Keeffe EB. Lamivudine therapy for chemotherapy-induced reactivation of hepatitis B virus infection. Am J Gastroenterol. 1999; 94: 249-51.

[70] Yeo W, Steinberg JL, Tam JS, et al. Lamivudine in the treatment of hepatitis B virus reactivation during cytotoxic chemotherapy. J Med Virol. 1999; 59: 263-9.

[71] Simpson ND, Simpson PW, Ahmed AM, et al. Prophylaxis against chemotherapy-induced reactivation of hepatitis B virus infection with Lamivudine. $J$ Clin Gastroenterol. 2003; 37: 68-71.

[72] Lim LL, Wai CT, Lee YM, et al. Prophylactic lamivudine prevents hepatitis B reactivation in chemotherapy patients. Alimentary pharmacology \& therapeutics. 2002; 16: 1939-44.

[73] Vassiliadis T, Garipidou V, Tziomalos K, Perifanis V, Giouleme O, Vakalopoulou S. Prevention of hepatitis B reactivation with lamivudine in hepatitis B virus carriers with hematologic malignancies treated with chemotherapy--a prospective case series. Am J Hematol. 2005; 80: 197-203.

[74] Martyak LA, Taqavi E, Saab S. Lamivudine prophylaxis is effective in reducing hepatitis $\mathrm{B}$ reactivation and reactivation-related mortality in chemotherapy patients: a meta-analysis. Liver Int. 2008; 28: 28-38.

[75] Loomba R, Rowley A, Wesley R, et al. Systematic review: the effect of preventive lamivudine on hepatitis B reactivation during chemotherapy. Ann Intern Med. 2008; 148: 519-28.

[76] Lok AS, Lai CL, Leung N, et al. Long-term safety of lamivudine treatment in patients with chronic hepatitis B. Gastroenterology. 2003; 125: 1714-22.

[77] Kim JS, Hahn JS, Park SY, et al. Long-term outcome after prophylactic lamivudine treatment on hepatitis B virus reactivation in non-Hodgkin's lymphoma. Yonsei medical journal. 2007; 48: 78-89.

[78] Law JK, Ali JA, Harrigan PR, Sherlock CH, Savage KJ, Yoshida EM. Fatal postlymphoma chemotherapy hepatitis B reactivation secondary to the emergence of a YMDD mutant strain with lamivudine resistance in a noncirrhotic patient. Am J Hematol. 2006; 81: 969-72.

[79] Perez-Roldan F, Gonzalez-Carro P, Villafanez-Garcia MC. Adefovir dipivoxil for chemotherapy-induced activation of hepatitis B virus infection. $N$ Engl $J$ Med. 2005; 352: 310-1.

[80] Fouillard L, Serfaty L, Gozlan J. Adefovir therapy for lamivudine escape and hepatitis B virus reactivation after reduced intensity conditioning allogeneic stem cell transplantation. Bone marrow transplantation. 2006; 37: 625-6.

[81] Fung SK, Chae HB, Fontana RJ, et al. Virologic response and resistance to adefovir in patients with chronic hepatitis B. J Hepatol. 2006; 44: 283-90.

[82] Kohrt HE, Ouyang DL, Keeffe EB. Antiviral prophylaxis for chemotherapyinduced reactivation of chronic hepatitis B virus infection. Clinics in liver disease.

2007; 11: 965-91, x. 
[83] Kohrt HE, Ouyang DL, Keeffe EB. Systematic review: lamivudine prophylaxis for chemotherapy-induced reactivation of chronic hepatitis B virus infection. Alimentary pharmacology \& therapeutics. 2006; 24: 1003-16.

[84] Lau GK, Yiu HH, Fong DY, et al. Early is superior to deferred preemptive lamivudine therapy for hepatitis B patients undergoing chemotherapy.

Gastroenterology. 2003; 125: 1742-9.

[85] Katz LH, Fraser A, Gafter-Gvili A, Leibovici L, Tur-Kaspa R. Lamivudine prevents reactivation of hepatitis $\mathrm{B}$ and reduces mortality in immunosuppressed patients: systematic review and meta-analysis. J Viral Hepat. 2008; 15: 89-102.

[86] Barclay S, Pol S, Mutimer D, et al. Erratum to 'The management of chronic hepatitis B in the immunocompromised patient: recommendations from a single topic meeting' [J. Clin. Virol. 41 (4) 2008 243-254]. J Clin Virol. 2008; 42: 104-15.

[87] Liu CJ, Kao JH, Chen DS. Kinetics of hepatitis B virus reactivation after chemotherapy: more questions than answers. Gastroenterology. 2006; 131: 1656; author reply -7.

[88] Hui CK, Cheung WW, Au WY, et al. Hepatitis B reactivation after withdrawal of pre-emptive lamivudine in patients with haematological malignancy on completion of cytotoxic chemotherapy. Gut. 2005; 54: 1597-603.

[89] Lin PC, Poh SB, Lee MY, Hsiao LT, Chen PM, Chiou TJ. Fatal fulminant hepatitis B after withdrawal of prophylactic lamivudine in hematopoietic stem cell transplantation patients. International journal of hematology. 2005; 81: 349-51.

[90] Lim SG, Wai CT, Rajnakova A, Kajiji T, Guan R. Fatal hepatitis B reactivation following discontinuation of nucleoside analogues for chronic hepatitis B. Gut. 2002; 51: 597-9.

[91] Saab S, Dong MH, Joseph TA, Tong MJ. Hepatitis B prophylaxis in patients undergoing chemotherapy for lymphoma: a decision analysis model. Hepatology. 2007; 46: 1049-56.

[92] Yeo W, Ho WM, Hui P, et al. Use of lamivudine to prevent hepatitis B virus reactivation during chemotherapy in breast cancer patients. Breast Cancer Res Treat. 2004; 88: 209-15.

[93] Liao CA, Lee CM, Wu HC, Wang MC, Lu SN, Eng HL. Lamivudine for the treatment of hepatitis B virus reactivation following chemotherapy for non-Hodgkin's lymphoma. Br J Haematol. 2002; 116: 166-9.

[94] Stroffolini T, Andriani A, Bibas M, Barlattani A. Successful treatment with lamivudine for reactivated hepatitis B infection following chemotherapy for nonHodgkin's lymphoma. Ann Hematol. 2002; 81: 48-9.

[95] Al-Taie OH, Mork H, Gassel AM, Wilhelm M, Weissbrich B, Scheurlen M. Prevention of hepatitis B flare-up during chemotherapy using lamivudine: case report and review of the literature. Ann Hematol. 1999; 78: 247-9. 


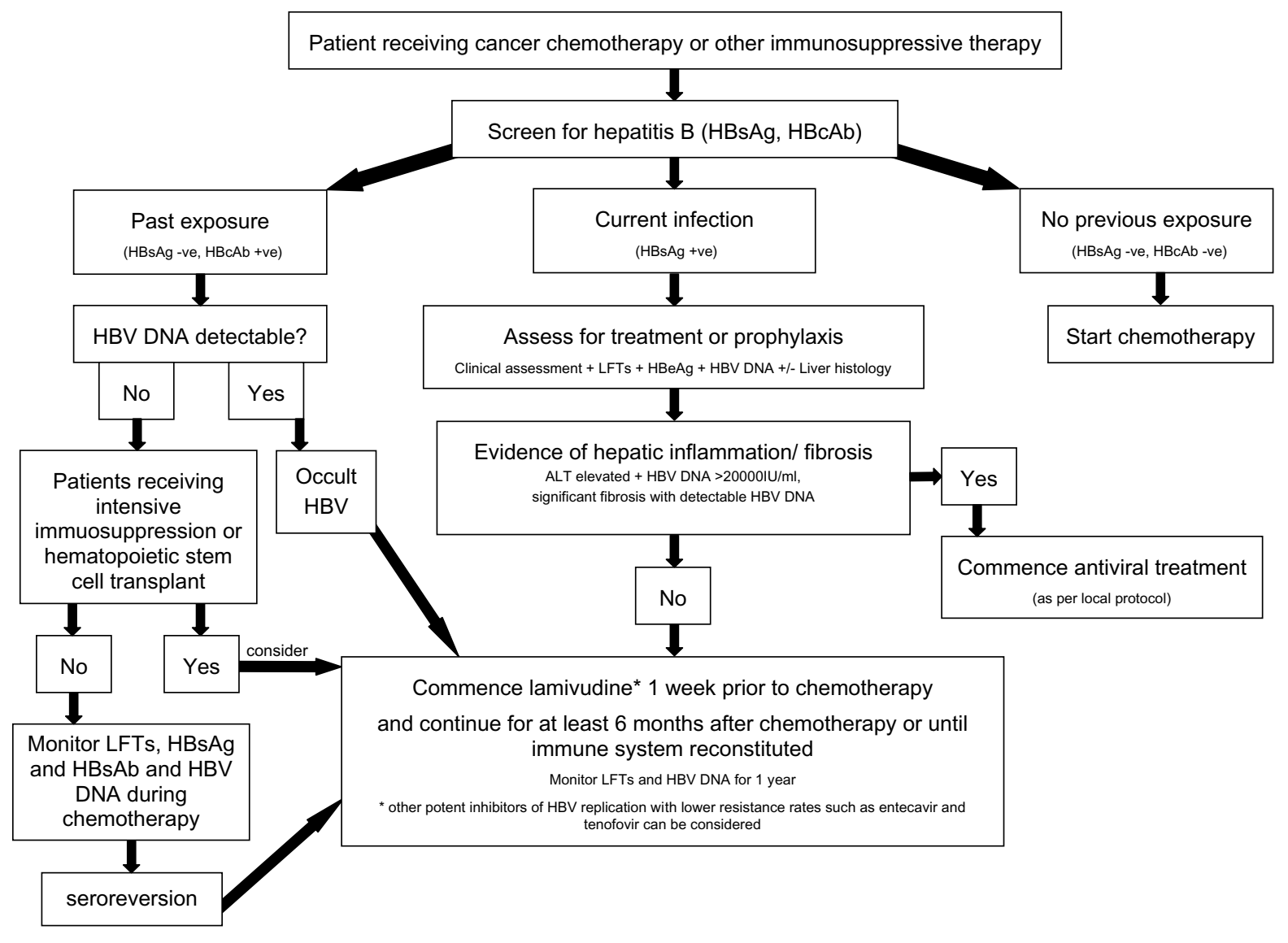

f1.eps 